\title{
Dual functionality anti-reflection and biocidal coatings
}

Heather M. Yates ${ }^{\mathbf{a}_{*}}$, Paul Sheel ${ }^{\mathbf{a}}$, John L. Hodgkinson ${ }^{\mathbf{a}}$, Michael E.A. Warwick ${ }^{\mathbf{a}}$, Souad O. Elfakhri $^{\mathbf{b}}$, Howard A. Foster ${ }^{\mathbf{b}}$

${ }^{a}$ Materials and Physics Research Centre, University of Salford, M5 4WT Salford, UK.

${ }^{\mathbf{b}}$ Biomedical Research Centre, School of Environment and Life Sciences, University of Salford, Salford, M5 4WT, UK.

*Correspondence: H.M.Yates@ Salford.ac.uk, phone +44 (0)161 295 3115, fax +44 (0)161 2955575

\begin{abstract}
A thin film combination of anti-reflection (AR) and biocidal properties would be of particular interest to reduce the transfer of infection and improve readability of public high use touch screens. In this paper we describe the development of a dual functionality film of silica (AR) and copper oxide (biocidal). Deposition was via flame assisted chemical vapour deposition (FACVD) which has the advantages of being a cost efficient atmospheric pressure technique enabling use of non-volatile precursors and that no closed reaction cell is required so making it ideal for integration into industrial production lines. The resulting films were characterized by a range of techniques including optical spectroscopy, electron microscope and X-ray fluorescence. Biocidal behavior was tested by determining the kill rate of Escherichia coli.
\end{abstract}

A 3 layer stack on glass of silica/copper oxide/silica had better adhesion and lower reflection than a comparable 2 layer stack. This multilayer film led to a $>2 \%$ drop in reflection from that of uncoated glass, similar to that of silica only film. In addition, showed a $>6 \log 10$ kill between 6 and $24 \mathrm{~h}$ for as deposited and annealed samples.

Keywords: biocidal, anti-reflection, APCVD, Silica, copper oxide 


\section{Introduction}

Copper and its oxides have long been known to have powerful anti-bacterial properties $[1,2,3]$ and more recently have been used as potential antifouling agents in membrane desalination processes [4]. These have been studied in conjunction with other materials such as $\mathrm{TiO}_{2}$ for dual antibacterial and self-clean surfaces $[5,6]$ as well as polymers for superhydrophobic antibacterial surfaces [7]. Another possibility would be use of silica combined with copper to produce a film with both anti-reflection (AR) and biocidal layers. AR films themselves are well known for uses in many optical systems including photovoltaics and displays which require reduced reflection and hence higher transmission of light. For example Hocine et al [8] showed a 3\% (absolute) increase in solar cell efficiency on addition of an AR film. In addition the use of silica films has included dual functionality AR with both superhydrophobic [9] and superhydrophilic [10] surfaces. A combination of copper (oxide) and silica would not only improve the durability of the copper containing layer, which is generally relatively soft, but provide an added value thin film with dual functionality.

The mechanical hardness and adhesiveness of a functional film is critical to successful extension of that material to possible commercial uses. Various groups have improved film durability by incorporation of copper nanoparticles within polymers by AACVD [7] or a polymer melting compounding method [11]. Alternatively via Flame-Spray deposition of $\mathrm{TiO}_{2}$ and $\mathrm{Cu}$ powers to form thick polished mechanically robust films [12]. One disadvantage of these films, particularly the latter, is their lack of transparency due to thickness and/or high levels of copper, which limits certain applications. To deposit films with AR capability as well as biocidal, the film must be transparent, particularly if targeted uses for such a film include high use touch screens in public places to reduce the transfer of infections and improve the readability of the screen. Automated check-in and ticket machines at train stations, airports or GP's surgeries would all benefit from such thin films. Another option is coatings for high usage personal items such as phones or tablets. 
The films are produced by FACVD [13], which has advantages over competitor technologies for depositing AR and biocidal coatings. Typically CVD precursors are supplied to a highly energetic propane/air gas flame. This breaks down the usually highly stable precursors into fragments, which subsequently nucleate and lead to the formation of a porous film on the substrate, whose properties can be tailored by choice of the deposition parameters. The process is attractive in terms of cost for both precursors which are often aqueous salts [14] and the relatively low cost of required equipment. One advantage of this technique is that no closed reaction cell is required, so making it ideal for fitting on open production lines. It also has the attraction of being a relatively low temperature $\left(<200^{\circ} \mathrm{C}\right.$ substrate temperature $)$ process.

Silica films produced by FACVD have porous structures where air filled voids provide a net reduction in index, minimizing the reflection at each interface and hence of lower refractive index than that of the glass substrate. Combining this with careful choice of film thickness will lead to an AR coating. This single stage process has advantages in terms of simplicity and scalability over more complex structures and routes for multilayer [15] or colloidal graded-index, 'moth eye' AR films [16].

We have previously achieved AR coatings with a greater than a $2 \%$ drop in reflection and transmission no lower than base glass [17]. The objective is to show that we can keep this behaviour, along with low optical haze and still provide a suitably active and durable biocidal surface. As far as we are aware this paper reports for the first time on the combination of AR and biocidal thin films, which were produced via an in-line multi-chemistry process. This paper explores the effects of deposition parameters and processing on the optical and biocidal properties of these dual function layers.

\section{Experimental}


2.1 Deposition - The FACVD reactor is made up of 3 main sections, these are: the burner head, substrate stage and precursor delivery system. The substrate stage is made up of a heated iron block, which can be moved backwards and forwards under the flame. The number of passes relating to the thickness of the film deposited. The maximum substrate handling capacity is $200 \mathrm{~mm}$ x $250 \mathrm{~mm}$. Full details of the system have been published previously [18].

Various arrangements and thicknesses of the AR and copper oxide layers were assessed for their effect on the optical properties and overall film durability. In each case the films were applied to the tin side of $3 \mathrm{~mm}$ float glass. Sample size was 100 x $100 \mathrm{~mm}$. Standard optimised AR conditions using tetraethylorthosilicate (TEOS) and copper oxide deposition are given in table 1 .

Table I, FACVD deposition conditions

\begin{tabular}{|c|c|c|c|}
\hline parameters & $\mathrm{SiO}_{2}($ coater 1$)$ & $\mathrm{SiO}_{2}($ coater 2$)$ & $\begin{array}{l}\text { Copper oxide } \\
\text { (coater } 2 \text { ) }\end{array}$ \\
\hline $\begin{array}{l}\text { Substrate } \\
\text { temperature }\end{array}$ & $200{ }^{\circ} \mathrm{C}$ & $200{ }^{\circ} \mathrm{C}$ & $200{ }^{\circ} \mathrm{C}$ \\
\hline $\begin{array}{l}\text { Flame } \\
\text { propane:air flow }\end{array}$ & $2.1: 40 \mathrm{~L} / \mathrm{min}$ & $1.0: 20 \mathrm{~L} / \mathrm{min}$ & $1.0: 20 \mathrm{~L} / \mathrm{min}$ \\
\hline Precursor & TEOS $1.2 \times 10^{-3} \mathrm{~mol} / \mathrm{min}$ & TEOS $1.2 \times 10^{-3} \mathrm{~mol} / \mathrm{min}$ & $\mathrm{CuSO}_{4}(\mathrm{aq}) 0.25 \mathrm{M}$ \\
\hline Nebuliser flow & N/A & N/A & $2 \mathrm{~L} / \mathrm{min}$ \\
\hline $\begin{array}{l}\text { Translation } \\
\text { stage speed }\end{array}$ & $20 \mathrm{~mm} / \mathrm{s}$ & $20 \mathrm{~mm} / \mathrm{s}$ & $20 \mathrm{~mm} / \mathrm{s}$ \\
\hline Line heating & $160{ }^{\circ} \mathrm{C}$ & $160^{\circ} \mathrm{C}$ & $140{ }^{\circ} \mathrm{C}$ \\
\hline
\end{tabular}

Silica-Copper oxide film structures were produced via FACVD depositing the layers sequentially using two separate burner heads and precursor delivery systems for the silica and copper. Initially the first silica layer (layer 1) was deposited onto the substrate using coater system 1 . The sample was removed and then placed onto coater 2 for deposition of the copper oxide layer. Finally, the sample was transferred back onto the first coater for the top silica layer deposition (layer 3). Separate coaters were used as a precaution to prevent possible 
copper contamination of lines /head as this may modify the properties of a silica AR layer subsequently being deposited on the same coater. Once the initial conditions had been established both materials were deposited on the same coater using two in-line burner heads supplied by independent delivery systems to mimic the multi-chemistry in-line production.

\subsection{Microbiological testing}

Antibacterial activity was determined according to the method based on BS ISO 27447:2009 [19], which has been described previously by us [20]. Firstly, all samples ( $2 \mathrm{~cm} \mathrm{x} 2 \mathrm{~cm})$ were sterilized for $20 \mathrm{~min}$ in $90 \%$ methanol in an ultrasonic bath. The samples were then placed in a sterile Petri dish and time given $(\geq 1 \mathrm{~h})$ to allow the methanol to evaporate. Escherichia coli ATCC 8739 was sub-cultured onto Nutrient Agar (NA, Oxoid, Basingstoke, UK) and incubated at $37^{\circ} \mathrm{C}$ for $24 \mathrm{~h}$. The bacteria colonies were then suspended in a 1:500 dilution of NB, which was adjusted to OD 0.01-0.02 at $600 \mathrm{~nm}$ in (Camspec, M330, Cambridge, UK) to give $\sim 2 \times 10^{7}$ colony forming units $(\mathrm{cfu}) / \mathrm{cm}^{3}$. Each test sample was inoculated with $50 \mu \mathrm{L}$ of this bacterial culture and then covered with a sheet of borosilicate glass to ensure close contact between the culture and the sample. The samples were placed in Petri dishes (50 mm diameter), which containing dampened filter paper. This was to prevent the suspensions drying out. The control samples were uncoated borosilicate glass $(1 \mathrm{~mm})$. After 0,6 and $24 \mathrm{~h}$ samples were removed and immersed in $20 \mathrm{~cm}^{3}$ of sterile Tryptone Soy broth (TSB, Oxoid). The bacteria were then resuspended by vortexing for $60 \mathrm{~s}$. A viability count was carried out by dilution and plating on NA in triplicate and incubation at $37^{\circ} \mathrm{C}$ for up to $48 \mathrm{~h}$. For repeat testing, samples were autoclaved for $15 \mathrm{~min}$ at $121^{\circ} \mathrm{C}$, washed in tap water, dried and resterilised in $90 \%$ ethanol as before.

\subsection{Film Characterisation}

The films were characterised via X-ray photoelectron spectroscopy (Kratos Axis Nova), with experimental data processed using the 'Casa XPS' software package. The scans were 
calibrated using the C1s binding energy of $285 \mathrm{eV}$. Surface copper concentrations were determined by X-ray Fluorescence Spectroscopy (Philips PW1480) using the copper K $\alpha$ line at $8.040 \mathrm{keV}$. To give an idea of the possible relative levels of copper that were detected in the samples an aluminium alloy standard containing $~ 500$ ppm of copper was also run. This should not be considered to be a definitive absolute measure as the matrix (aluminium) is different to the glass samples, and the response for copper might also be slightly different. Also, the copper in the aluminium standard is homogeneously distributed throughout the bulk rather than being present as a thin near-surface layer of copper oxide.

Film thicknesses were obtained by masking the substrate with 'Kapton' polyimide tape and measuring the resultant step using a 'Dektak 3ST' surface profiler. Reflection and transmission values were measured simultaneously between 400 and $800 \mathrm{~nm}$ using a visible/near IR fibre optic spectrophotometer (Ocean Optics, USB 2000+) and the associated 'SpectraSuite' software. A lab built spectrometer consisting of a $75 \mathrm{~W}$ xenon lamp and four broadband filters centring on four wavelengths (800, 650, 531, and $450 \mathrm{~nm}$ ) was used to measure optical scattering. A silica sample was used to calibrate the throughput of the integrating sphere.

Contact angle measurements were used to assess the hydrophobic nature of the films. A $10 \mu \mathrm{L}$ water drop was syringed onto the film and its diameter measured under an optical microscope. This was then used to determine the contact angle between the water and the film. The physical hardness of the films was assessed via a scratch test with a diamond scribe under a constant load of $100 \mathrm{~g}$. The width of the scratch gives a relative measure of film hardness. Mechanical durability was assessed by a lab-built wear test instrument to indicate the resistance to continuous finger swipes in a touch screen application. This unit translated the sample beneath a rubbing head which could be fitted with a range of friction materials and varying vertical load. 


\section{Results and discussion}

3.1 Optimisation of thin film structure - Initial work established that the thin film stacks consisted of silica and a mix of copper oxides. These were predominantly $\mathrm{Cu}_{2} \mathrm{O}$, but under different processing treatment more $\mathrm{CuO}$ was produced, as described later. Due to the possible presence of mixed oxides the copper oxide layers are denoted as $\mathrm{Cu}_{\mathrm{x}} \mathrm{O}$ within this paper. It was established that no more than 2 passes of $\mathrm{Cu}_{\mathrm{x}} \mathrm{O}(\sim 5-7 \mathrm{~nm})$ could be added before reflection and transmission dropped, as shown in figure 1. It was also found (via a 'scratch test') that a single copper containing layer was soft and easily damaged with a scratch width of $30.1 \pm 2.9 \mu \mathrm{m}$. In comparison a single $\mathrm{SiO}_{2}$ layer was much harder with a narrower scratch width of $6.8 \pm 1.4 \mu \mathrm{m}$. Deposition of $\mathrm{SiO}_{2}$ under $\mathrm{Cu}_{\mathrm{x}} \mathrm{O}$ gave a similar scratch width $(6.5 \pm 0.9 \mu \mathrm{m})$ and hence hardness to silica alone as the copper will predominantly fill the valleys in the rough silica undercoat and the silica peaks will predominate. Samples with $\mathrm{SiO}_{2}$ over $\underline{\mathrm{Cu}_{x}} \underline{\mathrm{O}}$ gave intermediate scratch values $(21.7 \pm 2.7 \mu \mathrm{m})$ and hence hardness between that of a single $\underline{\mathrm{Cu}_{\underline{x}}} \underline{\mathrm{O}}$ or $\mathrm{SiO}_{2}$ film. This confirmed the need to incorporate the $\underline{\mathrm{Cu}} \underline{\mathrm{x}} \underline{\mathrm{O}}$ within the much harder $\mathrm{SiO}_{2}$ film.

Air SEM's (figure 2) showed the $\mathrm{SiO}_{2}$ surfaces to consist of closely packed, small, slightly irregular particles whether just $\mathrm{SiO}_{2}$ or $\mathrm{SiO}_{2}$ over $\mathrm{Cu}_{\mathrm{x}} \mathrm{O} . \mathrm{A} \mathrm{Cu}_{\mathrm{x}} \mathrm{O}$ only film showed island growth of small, smooth particles spread over the surface. The $\mathrm{SiO}_{2}$ under $\mathrm{Cu}_{\mathrm{x}} \mathrm{O}$ system is probably a mix of $\mathrm{SiO}_{2}$ and $\mathrm{Cu}_{\mathrm{x}} \mathrm{O}$ particles (particularly as the $\mathrm{Cu}_{\mathrm{x}} \mathrm{O}$ does not cover the whole surface).

Two layer systems of glass/ $\mathrm{Cu}_{\mathrm{x}} \mathrm{O} / \mathrm{SiO}_{2}$ were tested, which showed slightly higher reflection and slightly lower transmission than comparable 3 layer systems. In addition there was some concern about the adhesion of a $\mathrm{Cu}_{\mathrm{x}} \mathrm{O} / \mathrm{SiO}_{2}$ system over a $\mathrm{SiO}_{2} / \mathrm{Cu}_{\mathrm{x}} \mathrm{O} / \mathrm{SiO}_{2}$ system on glass. Due to this it was decided to concentrate on the 3 layer system. Use of a 3 layer $\mathrm{SiO}_{2} / \mathrm{Cu}_{\mathrm{x}} \mathrm{O}$ $/ \mathrm{SiO}_{2}$ structure was tested showing that addition of more than 4 passes of $\mathrm{SiO}_{2}$ on either side 
of the fixed $\mathrm{Cu}$ layer led to unacceptable drops in transmission although limited change in reflection. However, measurements of optical haze confirmed the increased surface roughness and increase in haze as the number of $\mathrm{SiO}_{2}$ passes (thickness) increased whether on layer 1 or layer 3. This can be seen clearly in Figure 3 which shows the increase in optical haze when either layer 1 or 3 is increased in thickness. In just about all cases a 3 layer structure does show greater haze than that of a comparable standard $\mathrm{SiO}_{2}$ only AR coating (1.2\% @ 450 $\mathrm{nm})$.

A selection of 3-layered structures ( $\mathrm{glass} / \mathrm{SiO}_{2} / \mathrm{Cu}_{\mathrm{x}} \mathrm{O} / \mathrm{SiO}_{2}$ ) were analysed by XPS (Figure 4). All samples, as would be expected, showed the presence of a strong Si 2p signal at $103.6 \mathrm{eV}$ characteristic of $\mathrm{SiO}_{2}$. There was no shift in position from that obtained from a $\mathrm{SiO}_{2}$ only film, suggesting that the $\mathrm{Cu}_{\mathrm{x}} \mathrm{O}$ and $\mathrm{SiO}_{2}$ are chemically distinct. The $\mathrm{O} 1 \mathrm{~s}$ peak at $532.9 \mathrm{eV}$ (in both the 3 layered structure and the single $\mathrm{SiO}_{2}$ film), confirms the presence of $\mathrm{O}^{2-}$ attached to $\mathrm{Si}^{4+}$ [21]. In addition there are two much smaller $\mathrm{O} 1 \mathrm{~s}$ peaks at $531.3 \mathrm{eV}$ and 533.6 $\mathrm{eV}$, which are related to absorbed water [22] and C-O bonds respectively [23]. The latter is probably due to either to surface contamination or incorporated via the organic precursor during deposition.

XPS only detects chemical species within the first few nm of the film surface, so unless any $\mathrm{Cu}_{\mathrm{x}} \mathrm{O}$ is on the surface it will not be detected. Within the wide scan the $\mathrm{Cu} 2 \mathrm{p}$ was hardly distinguishable and had a low signal/noise ratio when detected within the high resolution spectra. The binding energies for $\mathrm{Cu}(0), \mathrm{Cu}(1)$ and $\mathrm{Cu}$ (11) all lie within $1.2 \mathrm{eV}$ of each other making assignment more difficult. However, $\mathrm{Cu}$ (II) tends to have high intensity spin up satellites and broader peaks than $\mathrm{Cu}(\mathrm{l})$ and $\mathrm{Cu}(0)$. In the samples in which $\mathrm{Cu}_{\mathrm{x}} \mathrm{O}$ was detected on the surface fitting established the presence of mainly $\mathrm{Cu}_{2} \mathrm{O}$ with the $2 \mathrm{p}_{3 / 2}$ at 933.2 $\mathrm{eV}$, with some $\mathrm{CuO}$ at $934.7 \mathrm{eV}$. The $\mathrm{CuO}$ signal was also approximately $60 \%$ broader than that for the $\mathrm{Cu}_{2} \mathrm{O}$, in agreement with the literature [24]. 
The $\mathrm{Cu} 2 \mathrm{p}$ analysis established that the top $\mathrm{SiO}_{2}$ layer could be no more than about $50 \mathrm{~nm}$ thick (2 passes) as no sign of any copper migration for $100 \mathrm{~nm}$ (4 passes). Also use of less $\mathrm{Cu}_{\mathrm{x}} \mathrm{O}(2$ passes $)$ showed hardly any $\mathrm{Cu}$ ions reached the surface. In consideration of this data structures of formation 2-2-2, 2-4-2 and 2-2-4 (number of passes under fixed deposition parameters) were concentrated on as these keep the reflection low, transmission high and haze relatively small.

Having determined the major deposition parameters all the following measurements were on three layer samples (glass $/ \mathrm{SiO}_{2} / \mathrm{Cu}_{\mathrm{x}} \mathrm{O} / \mathrm{SiO}_{2}$ ) deposited entirely on coater 2 , using separate precursor delivery systems and in-line burner heads for the silica and copper oxide. Separate precursor delivery and burner heads were used to prevent chemical cross-contamination of the individual layers in the film.

3.1.1 Effects of annealing - Samples were also annealed in air at a set-point of $500{ }^{\circ} \mathrm{C}$ to encourage copper ion migration to the surface. The XPS (figure 4) showed that annealing for $<30$ minutes increased the concentration of $\mathrm{Cu}$ species on the surface. This also led to an increased amount of $\mathrm{Cu}$ (II) to $\mathrm{Cu}(\mathrm{I})$, as seen by the increased intensity of the shake-up satellite peaks, along with greater intensity of the $\mathrm{Cu} 2 \mathrm{p}_{3 / 2}$ peak at $934.7 \mathrm{eV}$ relating to the $\mathrm{Cu}$ (11).

The levels of $\mathrm{Cu}$ species were close to the detection limits of the XPS instrument so lacking high accuracy in determining the exact overall ratio of $\mathrm{Cu}_{2} \mathrm{O}$ to $\mathrm{CuO}$. An alternative more sensitive technique of X-ray Fluorescence Spectroscopy (XRF) was then used. Table 2 indicates a general increase in surface copper on annealing. Unfortunately, XRF is unable to distinguish the oxidation state of this copper.

Optical measurements for a 2-4-2 stack showed an increase in haze with annealing time (Table 2), possibly due to increased surface disorder with the increased level of $\mathrm{Cu}_{\mathrm{x}} \mathrm{O}$. In 
addition there was an increase in transmission possibly due to the greater dispersion of $\mathrm{Cu}$ ions throughout the $\mathrm{SiO}_{2}$ films and corresponding decrease in reflection.

Table II, Optical and XRF data for various annealing times

\begin{tabular}{lllll}
\hline $\begin{array}{l}\text { Anneal Time } \\
\text { (minute) }\end{array}$ & $\begin{array}{l}\text { Average R } \\
\text { 400-800nm }(\%)\end{array}$ & $\begin{array}{l}\text { Average T } \\
\text { 400-800nm }(\%)\end{array}$ & $\begin{array}{l}\text { Average haze } \\
(\%)\end{array}$ & $\begin{array}{l}\text { Copper } \\
\text { concentration } \\
(\mathrm{ppm})\end{array}$ \\
\hline 0 & 5.3 & 81.1 & 1.2 & 62 \\
30 & 4.5 & 84.4 & 2.5 & 143 \\
60 & 4.4 & 84.7 & 2.6 & 124 \\
\hline
\end{tabular}

3.1.2 Effects of surface preparation - The silica films have some surface powder as deposited, so in the interests of consistency and durability, the films were washed using a dilute solution of Micro $90^{\circledR}$, rinsed with water followed by IPA and allowed to dry before over coating with $\mathrm{Cu}_{\mathrm{x}} \mathrm{O}$ or analysis. To test the effects of the washing stage similar 3 layer films were deposited with and without a washing stage after the first silica layer was deposited (Table 3).

Table III, Comparison of the optical properties of samples prepared with or without an additional washing stage.

\begin{tabular}{lllll}
\hline Sample & $\begin{array}{l}\text { Washed } \\
1^{\text {st }} \text { layer Silica }\end{array}$ & $\begin{array}{l}\text { Average R } \\
800 \mathrm{~nm}(\%)\end{array}$ & $\begin{array}{l}\text { Average T } \\
800 \mathrm{~nm}(\%)\end{array}$ & $\begin{array}{l}\text { Average Haze } \\
(\%)\end{array}$ \\
\hline $2-2-2$ & no & 5.4 & 89.3 & 1.2 \\
$2 \mathrm{~W}-2-2$ & yes & 4.5 & 88.1 & 2.5 \\
$2-4{ }^{\prime}-2$ & no & 4.6 & 90.6 & 2.0 \\
$2 \mathrm{~W}-4$ '-2 & yes & 4.4 & 88.9 & 2.5 \\
\hline
\end{tabular}

Washing made no particular change to the reflection and transmission, for both as grown and annealed samples. However, optical haze increased for the 3 layer stack, when the sample was washed after depositing the first layer. This seems counter-intuitive that removing particles gives a hazier and possibly rougher top surface. One explanation is that use of the surfactant modifies the subsequent $\mathrm{Cu}_{\mathrm{x}} \mathrm{O}$ deposition. This has been previously seen with FACVD films of silver metal, which the surfactant seems to dramatically increase the deposition rate [25]. The increase in $\mathrm{Cu}_{\mathrm{x}} \mathrm{O}$ deposition was confirmed by the XRF data which showed for a 2-4-2 
stack a doubling of surface copper from $32 \mathrm{ppm}$ to $75 \mathrm{ppm}$. The lack of change in transmission may be due to the island growth nature of the $\mathrm{Cu}_{\mathrm{x}} \mathrm{O}$ layer [18] similar behaviour with FACVD silver [26]. Measurements of complete stack thickness showed no obvious increase in total thickness, suggesting the $\mathrm{Cu}_{\mathrm{x}} \mathrm{O}$ is partly embedded within the porous silica.

As higher levels of copper ions have a greater bacteria kill rate (as shown in section 3.3), it was decided to concentrate on 3 layer stacks which had been annealed and included a washing stage after the deposition of the first silica layer. These additional stages also had no detrimental effect on the transmission or reflection, although the increased haze was potentially an adverse problem.

3.2 Durability - As many of the AR-bio films target applications involve repeated physical contact and cleaning cycles, it was important to assess mechanical durability. The Scotch tape test is often used to test film adhesion, but for this work it would not be of sufficient severity. To this end, a specific wear test instrument was constructed to indicate the resistance to continuous finger swipes in a touch screen application.

This unit translated the sample beneath a rubbing head which could be fitted with a range of friction materials and varying vertical load. A brief experiment suggested that the typical force applied during normal touch screen use was in the range of $5-16 \mathrm{~g}$, so to accelerate this effect a minimum load of $76.5 \mathrm{~g}$ was selected for the initial trial. This was used in conjunction with a synthetic felt pad, deemed to be more abrasive than typical human skin. It was found that the 2-4-2 film was resistant to abrasion with 10,000 cycles, each representing two passes against the abrasion head, having minimal impact on the appearance of the film. This was supported by the transmission measurements taken at various intervals as given in figure 5 . Increasing the vertical load to $272.5 \mathrm{~g}$ resulted in a visible wear track and a small reduction in transmission after 1000 cycles.

\subsection{Biocidal testing}


Production of a biocidal surface using a copper or copper oxide film is comparatively straightforward. However, in this case where it is necessary to have a low $\mathrm{Cu}_{\mathrm{x}} \mathrm{O}$ concentration, so the high transmission and AR are retained is much more challenging.

3.3.1 Optimisation of samples - Initial screening tests with a 3 layer AR-bio non-optimised stack of glass $/ \mathrm{SiO}_{2} / \mathrm{Cu}_{\mathrm{x}} \mathrm{O} / \mathrm{SiO}_{2}$ (4-10-4) and a two layer glass $/ \mathrm{Cu} \mathrm{x}_{\mathrm{x}} \mathrm{O} / \mathrm{SiO}_{2}$ stack showed encouraging biocidal activity (figure 6). The initial coatings displaying a $>6 \log 10$ kill of $E$. coli bacteria (in $24 \mathrm{~h}$ ) and a $4 \log$ kill in $5 \mathrm{~h}$ for the glass $/ \mathrm{SiO}_{2} / \mathrm{Cu}_{\mathrm{x}} \mathrm{O}$ stack. The poorer kill rate for this sample may be due to the softer copper film being partially removed while being sterilised in an alcohol ultrasonic bath. In the other cases the top $\mathrm{SiO}_{2}$ protecting the $\mathrm{Cu}_{\mathrm{x}} \mathrm{O}$ layer.

Further tests of three layer stacks with AR optimised films were carried out to test the effects of amounts of $\mathrm{Cu}_{\mathrm{x}} \mathrm{O}$ (via number of passes). As can be seen in figure 7 the 2-4-2 configuration has a better kill rate than the 2-2-2 which ties in with the XPS result confirming the higher level of $\mathrm{Cu}_{\mathrm{x}} \mathrm{O}$ on the surface.

Using stacks of 2-4-2 as this showed a higher bio-activity than 2-2-2, the above test was repeated with new samples to look at the effects of annealing (Figure 8). These samples led to a $>6 \log$ kill between 6 and $24 \mathrm{~h}$. In these tests over $24 \mathrm{~h}$ no particular difference was seen between annealed and as deposited, although a steeper drop is seen for the annealed samples. Further tests were done at $16 \mathrm{~h}$ to determine more accurately the actual kill time, which showed the kill rate was approximately linear. It has previously been reported that $\mathrm{Cu}_{2} \mathrm{O}$ has a more efficient kill rate than $\mathrm{CuO}$ [27], so the lack of overall improvement in kill rate on annealing may be a balance of increased $\mathrm{CuO}$ (so lower biocidal activity) against the increased amount of $\mathrm{Cu}_{\mathrm{x}} \mathrm{O}$ on the surface.

So far the data has shown that it is possible to produce a multilayer film with AR and biocidal features which is relatively durable against constant rubbing (wear-test). However, it is very 
important that the films retain AR and biocidal properties after use. Further XRF was done to assess whether the concentration of $\mathrm{Cu}$ species on the surface was depleted. This was done using a 2-4-2 stack which had been annealed for 30 minutes.

The samples were analysed as deposited, after an initial sterilisation in methanol and after an initial bio-test and autoclave sterilisation. For the latter the samples had to go through a stringent autoclave procedure to safely neutralise all the bacteria before handling. The autoclave procedure consists of 15 minutes at $121^{\circ} \mathrm{C}$ in the autoclave, followed by washing with water then a 20 minute soaking in methanol. When the samples are in the sealed autoclave they will be surround by steam at $121^{\circ} \mathrm{C}$, due to an increased pressure of $15 \mathrm{psi}$ above atmospheric $\left(1.03 \times 10^{5} \mathrm{~N} / \mathrm{m}^{2}\right)$.

Table IV, Effects of the bio-test on surface copper concentrations.

\begin{tabular}{lll}
\hline \multicolumn{1}{c}{ Samples } & $\begin{array}{l}\text { Copper concentration } \\
\text { (ppm) }\end{array}$ \\
\hline & Set A & Set B \\
As deposited with 30 min anneal & 143 & 96 \\
sterilisation & 110 & 92 \\
After 1st biotest and autoclave sterilisation & 53 & 46 \\
After 2nd biotest and autoclave sterilisation & N/A & 36 \\
After 3rd biotest and autoclave sterilisation & N/A & 24 \\
\hline
\end{tabular}

As can be seen (Table 4, Set A), there is a loss of $\mathrm{Cu}$ after an initial sterilisation (20 minute ultra sound methanol clean), but a much greater one after the biotest and final autoclave treatment. This only reduces the level of $\mathrm{Cu}$ to that of an as deposited sample (62 ppm), which has been shown to efficiently kill bacteria (see Figure 8, '242 test'). It is not known whether the loss of $\mathrm{Cu}$ is due to the bio-testing or the use of the autoclave. This is an issue, as it is harsher than any treatment the film would have in a 'real life' situation.

3.3.2 Durability - Retention of functionality after bio-testing has not always been reported in the literature, despite being an important factor in assessing practical application. To determine whether the biocidal and AR properties could be retained under long term use the 
biocidal test was repeated three times on a single set of newly deposited 2-4-2 samples.

Between each bio-test the samples had to undergo the autoclave procedure, before repeating the test with a new bacteria culture. As seen in Figure 9, there was only a small increase in reflection and limited change in transmission after three tests, confirming the retention of the AR properties. Optical haze measurements showed a small decrease in values with increased number of bio-tests, suggesting a slight smoothing of the surface.

Unfortunately, the XRF data showed a reduction in $\mathrm{Cu}$ species from the surface after each bio-test (Table 4, Set B), which was reflected in the biocidal results (figure 10). The lack of complete kill after the first test can be attributed to the lower concentration of $\mathrm{Cu}$ ions in this sample (96 ppm) than the sample set used in the previous bio-test (143 ppm). Interestingly, the previous bio-test data showed full kill for the as deposited sample (not annealed), which only showed $62 \mathrm{ppm} \mathrm{Cu}$ on the surface. The difference in behaviour could relate to the change in surface roughness between the as deposited and annealed. The annealed samples, as shown by optical haze, were rougher, so possibly making it more difficult to either spread the $E$. coli cultures (so more concentrated) or to remove bacteria at the resuspension stage. Despite the loss of $\mathrm{Cu}$ the kill rate was similar for a repeat test on the same samples. It was only the $3^{\text {rd }}$ successive test that led to a reduced kill rate. It is important to note that the autoclave cycle needed to be repeated each time to confirm that no organisms were left. This clearly had an impact on the test results as it is far more abrasive than any long term weathering or wear test. A more representative bio-test may be to swab a coated constant use touch screen over a period of time to determine the change in bio-activity.

Another group which reported biocidal repeatability include Hassan et al [28] who monitored the biocidal activity of thick $\mathrm{Cu}(200-300 \mathrm{~nm})$ and $\mathrm{Cu}_{2} \mathrm{O}$ films $(400-1000 \mathrm{~nm})$ at 1,4 and 7 day intervals and concluded the reduction in the viable bacteria count was maintained. However, this is not directly comparable to our samples as their thick films will have a high concentration of copper species on the surface from which any depletion of copper species 
would have a negligible effect on the sample biocidal activity. In addition the treatment of the samples between tests seems less harsh, with only the aliquots of bacterial suspension being vortexed to release the bacteria and not the actual samples. Although the paper also states the samples were cleaned in methanol before the repeat tests.

In order to gain insight into possible variation in surface wetting as a result of bio-testing procedure and hence variation in the ability to spread the $E$. coli cultures the contact angle was taken of each sample after each round of bio-testing. It was found that there was little variation in the contact angle $\left(21^{\circ} \pm 2^{\circ}\right)$ as an effect of the repeated bio-testing indicating little change in the wetting behaviour and hence no change in the ability to spread the cell cultures.

\section{Conclusion}

The optimised form was a three layer stack of silica/copper oxide/silica, annealed at $500{ }^{\circ} \mathrm{C}$ for 30 minutes. This was physically durable as shown by its wear resistance, retained the AR properties (> $2 \%)$ and hence improved readability of a touch screen.

This multilayer stack also showed an ability to kill the test bacteria (E. coli) within $24 \mathrm{~h}$. Repeated bio-testing was done on a set of samples to determine if the films would be suitable for long term use. After three tests the AR properties were retained, but the biocidal properties reduced after the third repeat. However, the required autoclave sterilisation procedures after each test may also be an issue, as these are far more agressive than, for example, long term use of touch screens in public places to reduce the transfer of infections.

In addition we have demonstrated the multi-chemistry film in-line deposition possible by FACVD, to sequencially add $\mathrm{SiO}_{2}$ and $\mathrm{Cu}_{\mathrm{x}} \mathrm{O}$ layers within a single experiment.

\section{Acknowledgements}

We would like to thank B-Nano Ltd for the airSEM images, the NEXUS national facility for the XPS data and Keith Raper at LPD Lab Services Ltd for the XRF analysis. This work was 
financed by Framework 7 grant FP7 NMP.2012.1.4-1 309530 PLIANT “Process line

implementation for applied surface nanotechnologies".

\section{References}

[1] H.H.A. Dollwet, J.R.J. Sorenson, Historic uses of copper compounds in medicine, Trace Elem. Med. 2 (1985) 80-87.

[2] G. Borkow, J. Gabbay, Copper as a biocidal tool, Curr. Med. Chem. 12 (2005) 2163-2175.

[3] J.O. Noyce, H. Michels, C.W. Keevil, Use of copper cast alloys to control Escherichia coli O157 cross-contamination during food processing, Appl. Environ. Microbiol. 72 (2006) 42394244.

[4] M. Ben-Sasson, X. Lu, S. Nejati, H. Jaramillo, M. Elimelech, In situ surface functionalization of reverse osmosis membranes with biocidal copper nanoparticles, Desalination, 388 (2016) 1-8.

[5] H.M. Yates, L.A. Brook, I.B. Ditta, P. Evans, H.A. Foster, D.W. Sheel, A. Steele, Photoinduced self-cleaning and biocidal behaviour of titania and copper oxide multilayers, J. Photochem. Photobiol., A 197 (2008) 197-205.

[6] H.A. Foster, D.W. Sheel, P.Evans, P. Sheel, S. Varghese, S O. Elfakhri, J.L.Hodgkinson, H.M.Yates, Antimicrobial activity against hospital related pathogens of dual layer $\mathrm{CuO}-\mathrm{TiO}_{2}$ coatings prepared by CVD, Chem. Vapor Depos. 18 (2012) 140-146.

[7] E.Ozkan, C.C. Crick, A. Taylor, E. Allan, I.P. Parkin, Copper-based water repellent and antibacterial coatings by aerosol assisted chemical vapour deposition, Chem. Sci. 7 (2016) 5126-5131.

[8] D. Hocine, M.S. Belkaid, M. Pasquinelli, L. Escoubas, J.J. Simon, G.A. Riviere, A. Moussi, Improving efficiency of multicrystalline silicon solar cells by $\mathrm{TiO}_{2}$ antireflection coatings derived by APCVD process, Mater.Sci.Semicond.Proc.16 (2013)113-117.

[9] T.Ren, Z. Geng, J. He, X. Zhang, J. He, A versatile route to polymer-reinforced, broadband antireflective and superhydrophobic thin films without high-temperature treatment, J.Colloid. Interface Sci. 488 (2017) 1-7.

[10] J. Chen, L. Zhang, Z. Zeng, G. Wang, G. Liu,W. Zhao, T. Ren, Q. Xu, Facile fabrication of antifogging, antireflective, and self-cleaning transparent silica thin coatings, Colloids Surf.A, 509 (2016) 149-157.

[11] A. Kubacka, M. Ferrer, M. Fernandez-Garcia, Kinetics of photocatalytic disinfection in $\mathrm{TiO}_{2}$ containing polymer thin films:UV and visible light performances, Appl.Cat.B 121-121 (2012) 230-238.

[12] N. George, M. Mahon, A. McDonald, Bacterial performance of Flame-sprayed nanostructured titania-copper composite coatings, J.Thermal Spray Technol. 19 (2009) 10421053. 
[13] A.T. Hunt, W.B. Carter, J.K. Cochran, Combustion CVD - A novel thin film deposition technique, Appl. Phys. Lett. 63 (1993) 266-268.

[14] H.A.Foster, D.W. Sheel , P.Sheel, P.Evans, S.Varghese, N. Rutschke, H.M. Yates, Antimicrobial activity of titania/silver and titania/copper films prepared by CVD

J.Photochem.Photobiol., A 216 (2010) 283-289.

[15] Y. Li, K. Yang, B. Xia, B. Yang, L. Yan, M. He, H. Yan, B. Jiang, Preparation of mechanically stable triple layer interference broadband antireflective coatings with selfcleaning property by sol-gel technique, RSC.Adv. 7 (2017) 14660-14668.

[16] L. Chan, A. Ghoshal, E.A. DeCuir, Y.P. Chen, D.E. Morse, M.J. Gordon, Fabrication and optical behavior of graded-index, moth-eye antireflective structures in CdTe, J.Vac.SciTechnol., B35 (2017) 01120.

[17] H.M. Yates, J.L. Hodgkinson, R.W. Tandy, Durable high performance antireflection coatings via atmospheric pressure processing, Phys.Stat.Sol. A, 212 (2015)1544-1549.

[18] H.M. Yates, L.A. Brook, D.W. Sheel, I.B. Ditta, A.Steele, H.A. Howard, The growth of copper oxides by FACVD, Thin Solid Films, 517 (2008) 517-521.

[19] Anon. BS ISO 27447:2009 Fine ceramics (advanced ceramics, advanced technical ceramics) - Test method for antibacterial activity of semiconducting photocatalytic materials. British Standards Institution, London 2009.

[20] S. Varghese, S. O. ElFakhri, D.W. Sheel, P. Sheel, F.J. Bolton, H.A. Foster, Antimicrobial activity of novel nanostructured $\mathrm{Cu}-\mathrm{SiO} 2$ coatings prepared by chemical vapour deposition against hospital related pathogens, AMB Express 3 (2013) article 53.

[21] E. Paparazzo, M. Fanfoni, E. Severini, Studies on the structure of the $\mathrm{SiO}_{\mathrm{x}} / \mathrm{SiO}_{2}$ interface, Appl.Surf.Sci. 56 (1992) 866-872.

[22] Y. Sun, T. Egawa, L. Zhang, X. Yao, Effect of collection distance on the lattice structure of anatase titania nanoparticles prepared by Metal Organic Chemical Vapor Deposition, Jpn.J.Appl.Phys. 41 (2002) L1389-L1392.]

[23] J. Guillot, A. Jouaiti, B. Domenichini, O. Heintz, S. Zerkout, A. Mosser, S. Bourgeois, Nitrogen plasma pressure influence on the composition of $\mathrm{TiN}_{\mathrm{x}} \mathrm{O}_{\mathrm{y}}$ sputtered films, Surf. Interface Anal. 33 (2002) 577-582.

[24] S. Poulston, P.M. Parlett, P. Stone, M. Bowker, Surface oxidation and reduction of CuO and $\mathrm{Cu}_{2} \mathrm{O}$ studied using XPS and XAES, Surf. Interface Anal. 24 (1996) 811-820.

[25] P. Youngson, PhD thesis, University of Salford 2009.

[26] D.W. Sheel, L.A. Brook, H.M.Yates, Controlled nanostructured silver coated surfaces by Atmospheric Pressure Chemical Vapour Deposition, Chem.Vapor Depos. 14 (2008) 14-24. 
[27] S. Meghana, P. Kabra, S. Chakraborty, N. Padmavathy, Understanding the pathway of antibacterial activity of copper oxide nanoparticles, RSC.Adv.5 (2015) 12293-12299.

[28] I.A. Hassan, I.P. Parkin, S.P. Nair, C.J. Carmalt, Antimicrobial activity of copper and copper (1) oxide thin films deposited via aerosol-assisted CVD, J.Mater.Chem.B 2 (2014) 2855-2860.

\section{List of figures captions}

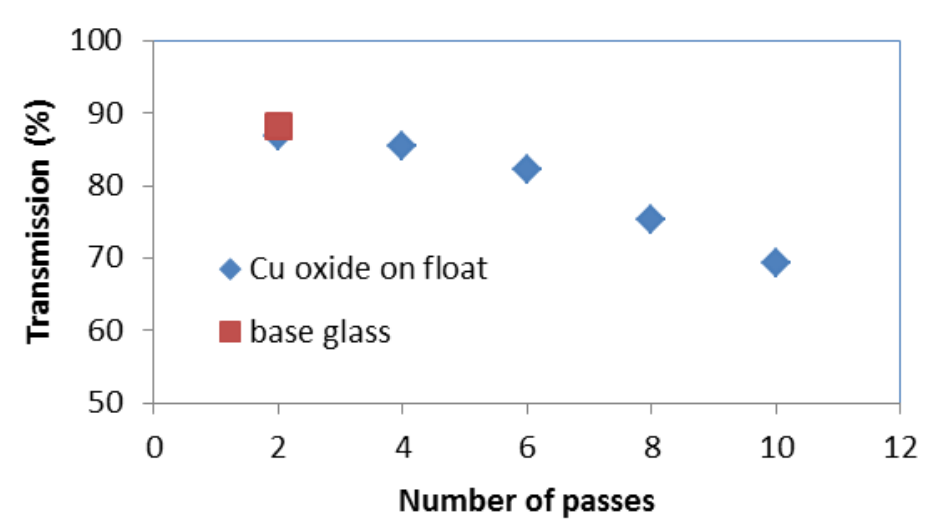

Figure 1, Effect of the amount of $\mathrm{Cu}_{\mathrm{x}} \mathrm{O}$ on film optical transmission (@550 nm).
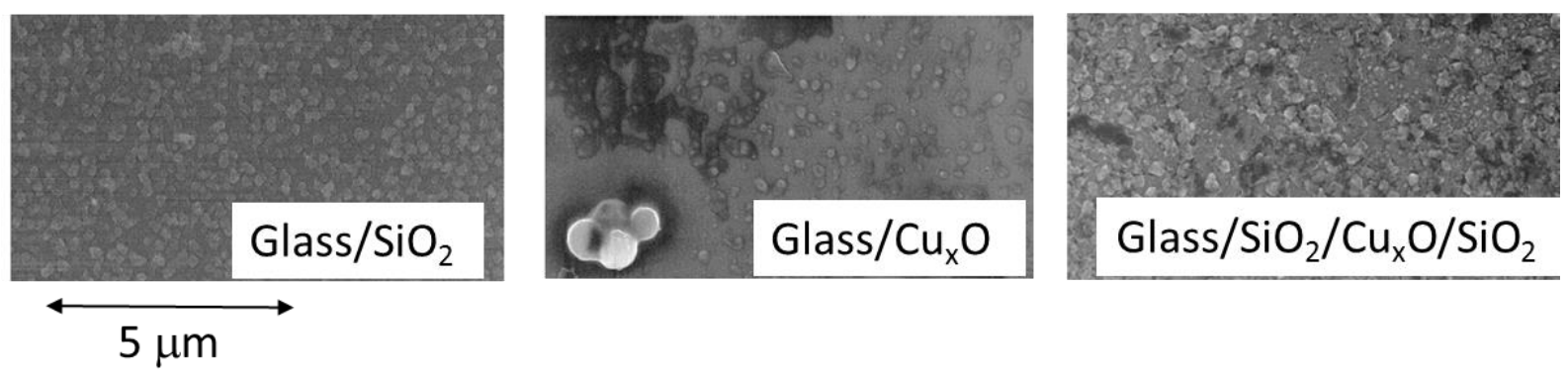

Figure 2, AirSEM images of surface morphologies. 

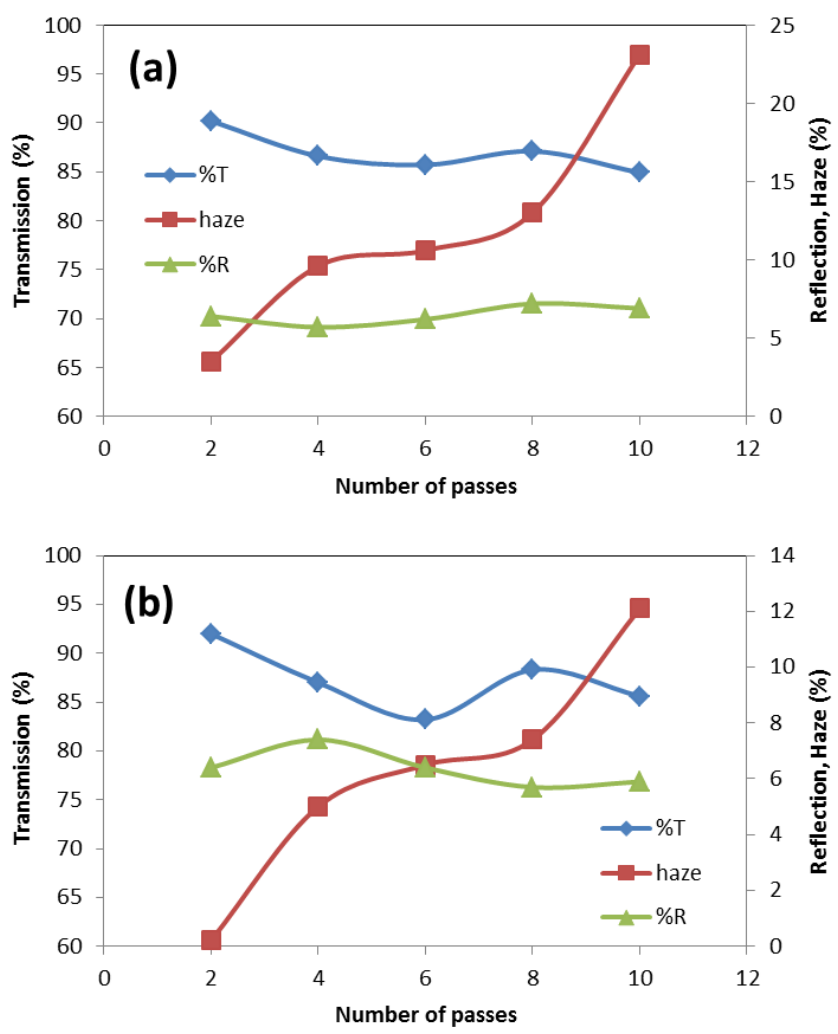

Figure 3, Optical data (at $450 \mathrm{~nm}$ ) for the three layered structure with fixed $\mathrm{Cu}_{\mathrm{x}} \mathrm{O}$ thickness (2 passes). (a) changes to layer 1, (b) changes to layer 3

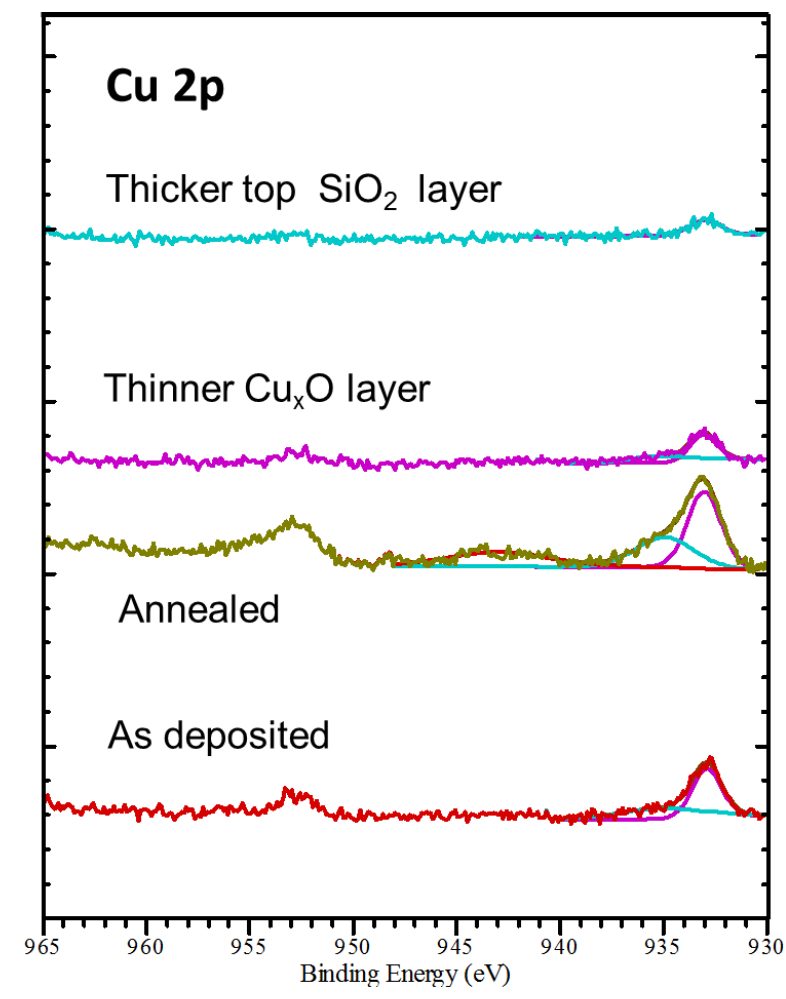

Figure 4, XPS showing the $\mathrm{Cu} 2 \mathrm{p}$ under various FACVD deposition conditions. 


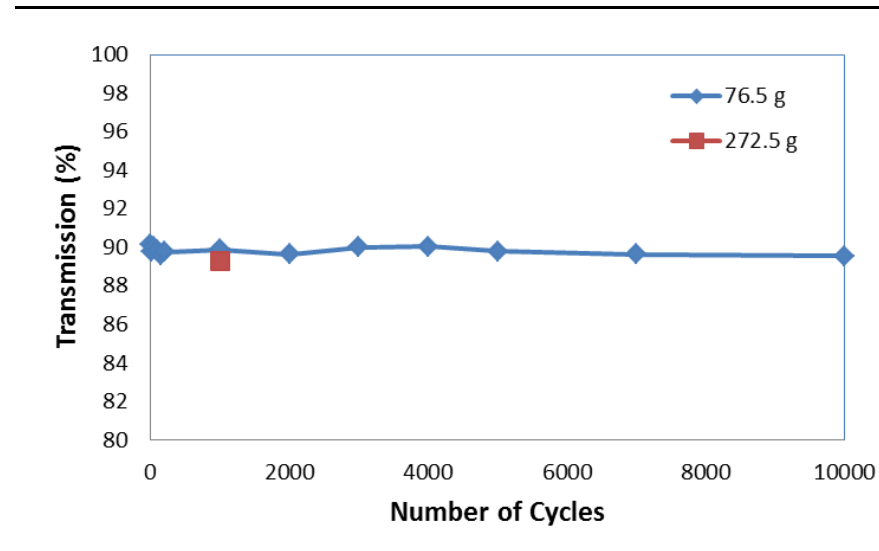

Figure 5, Wear test results showing the abrasion resistance of the 2-4-2 $\mathrm{SiO}_{2} / \mathrm{Cu}_{\mathrm{x}} \mathrm{O} / \mathrm{SiO}_{2}$ film.

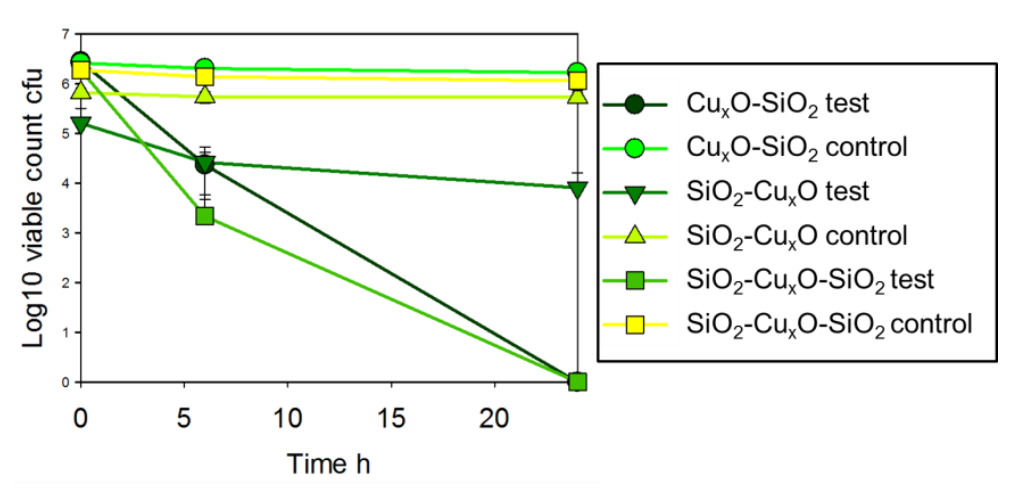

Figure 6, Killing of E. coli on AR coatings.

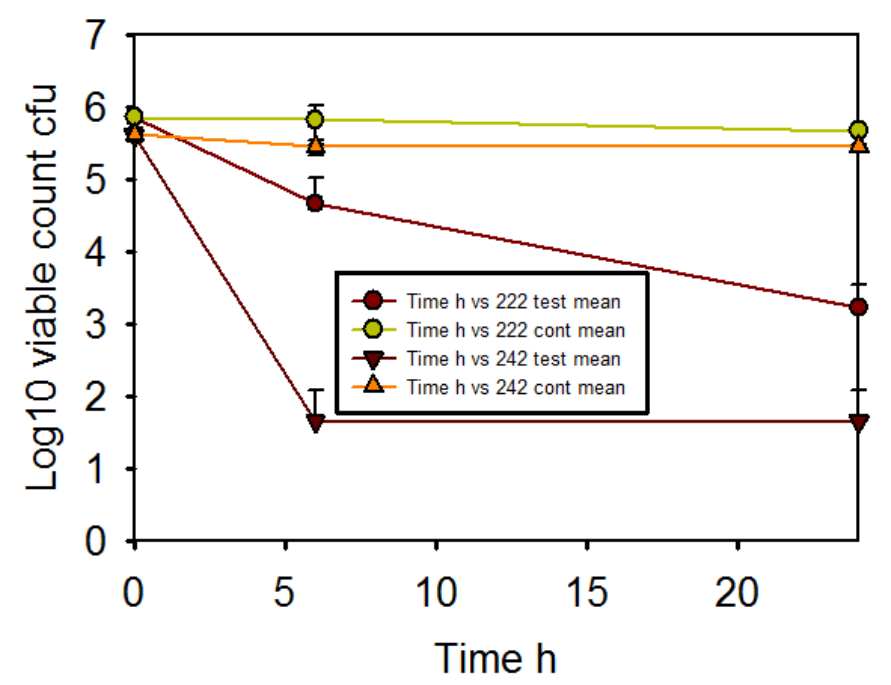

Figure 7, Comparison of kill rate for lower (2-2-2) and higher (2-4-2) concentration of $\mathrm{Cu}_{\mathrm{x}} \mathrm{O}$ in the stack. 


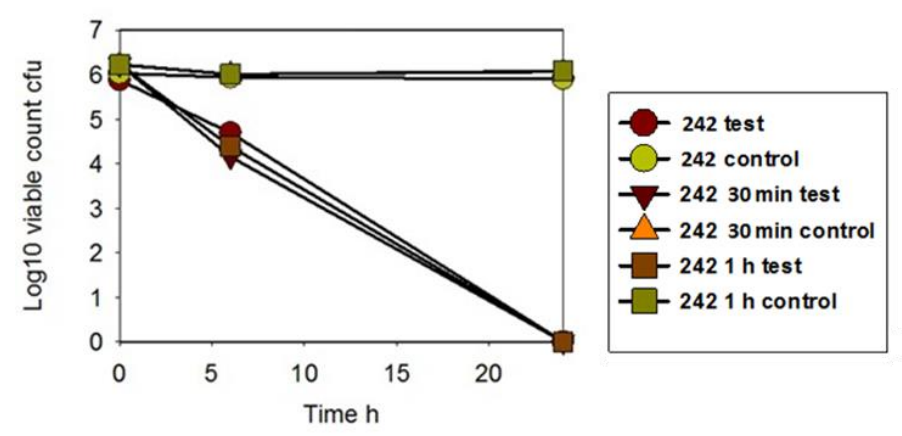

Figure 8, Comparison of the kill rate for samples with different annealing times.

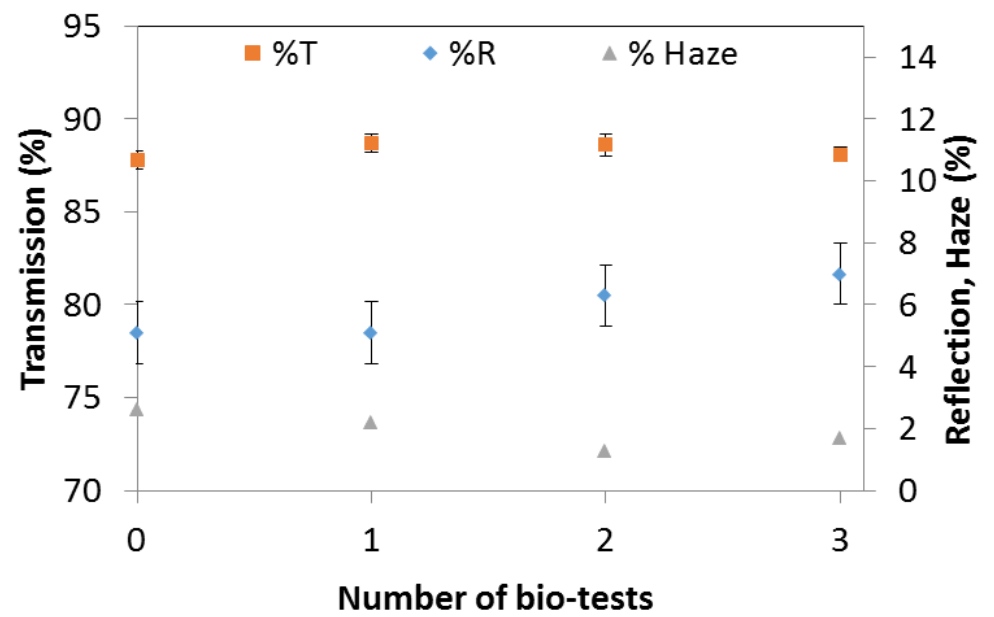

Figure 9, Optical properties against number of repeated bio-tests.

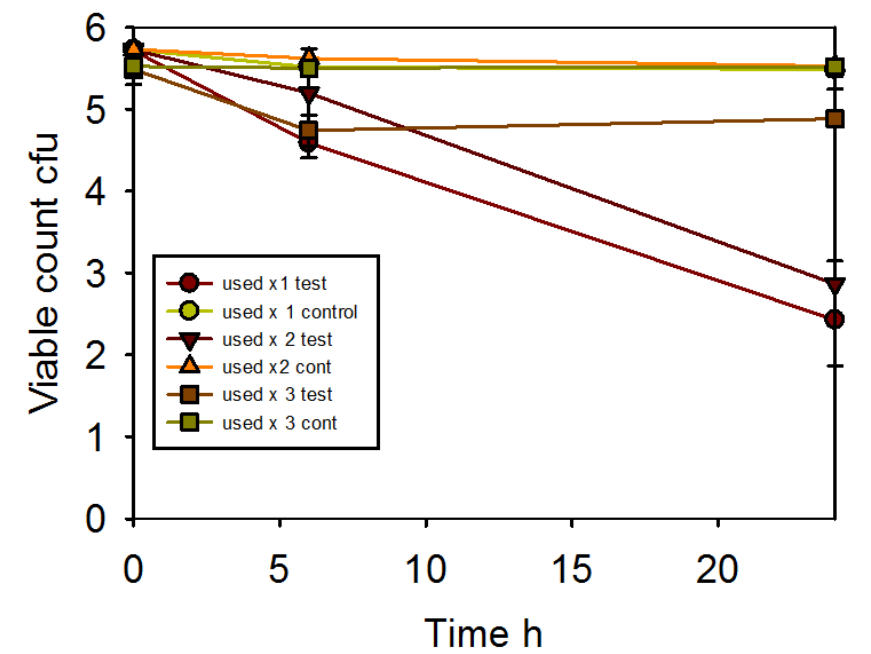

Figure 10, Bio-test data for repeated testing of the same samples. 